\title{
A Química na época dos Descobrimentos
}

\author{
II Encontro do Instituto D. João V - Os Descobrimentos e as Ciências
}

A N A E PEDO VAZ PINTO

«Por mares nunca antes navegados»... construíram os nossos heróicos navegadores pontes para o que, hoje, se veio a revelar um tremendo desafio para as sociedades modernas: a globalização.

Após as grandes explorações marítimas, as relevantes transformações no Ocidente e no Mundo marcaram o início de uma nova era na História da Humanidade ao nível económico, social, científico e artístico. A Europa apoderou-se do comércio do Oriente e da Ásia. Co- nheceram-se novas culturas, novos climas, novas terras e novas civilizações. Novos avanços na Ciência e na Técnica alteraram os conceitos e a forma de vida do Homem.

Todos os feitos dos Descobrimentos são grandiosos, mas aqueles que hoje podem servir de estímulo ao desenvolvimento e mobilização dos portugueses, em especial dos jovens, devem ser particularmente enaltecidos: o papel fundamental do espírito científico, presente nos navegadores, a grande abertura ao relacionamento cordial e de partilha com os outros povos, bem como a extraordinária eficácia na acção de mediação entre diferentes culturas.

"Os Descobrimentos e as Ciências" foi, pois, a temática que serviu de mote ao que denominámos "2. ${ }^{\circ}$ Encontro do Instituto $\boldsymbol{D}$. João $\boldsymbol{V}^{\prime}$, cujos protagonistas foram os 1600 alunos da nossa unidade escolar, repartidos pelo Ensino Básico e Secundário, e os alunos dos agru-

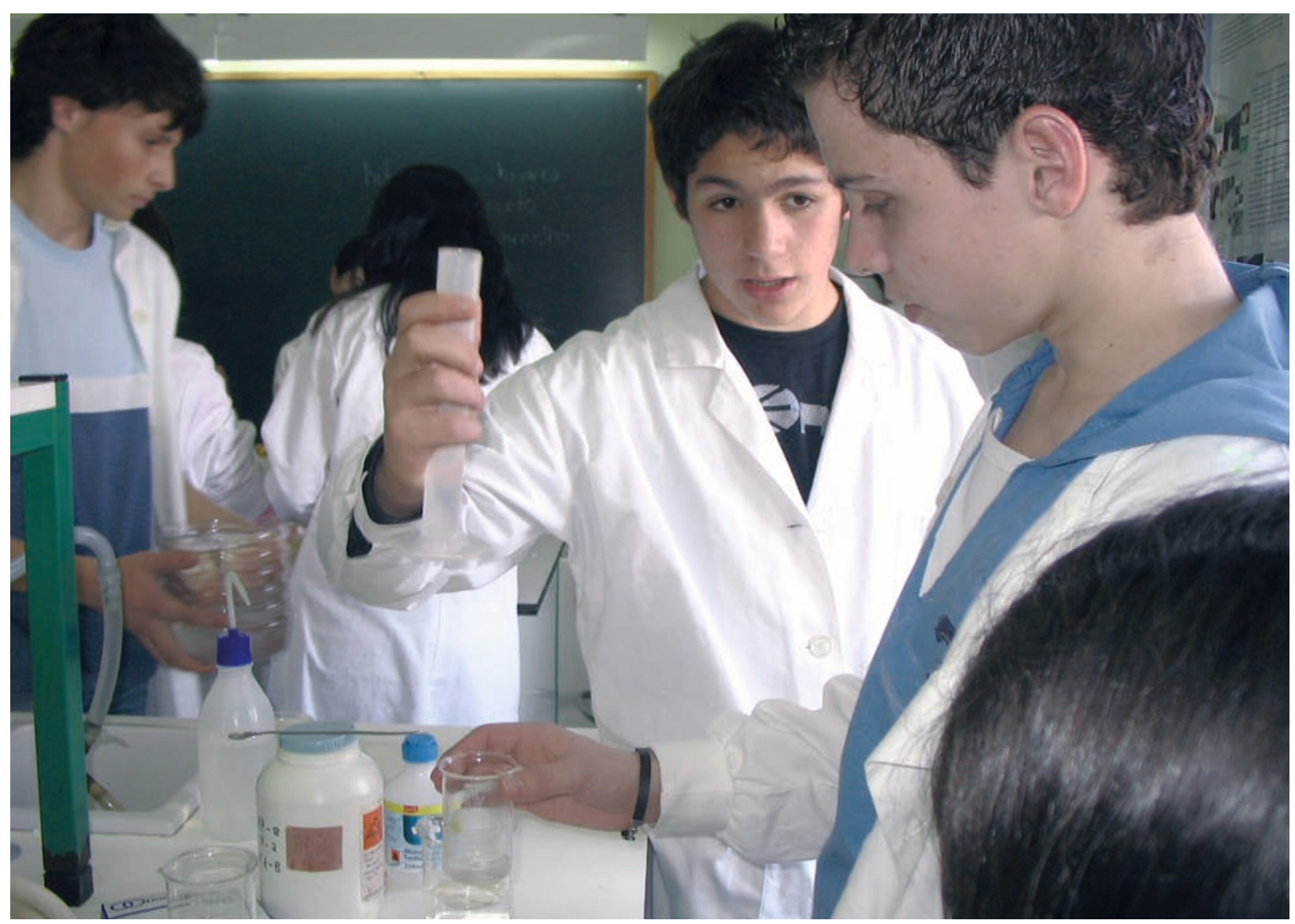

Produção de sabão 
pamentos das escolas do $1 .^{\circ}$ Ciclo da nossa área pedagógica.

\section{"A Química na Época dos Descobri-} mentos" foi o título da exposição interactiva preparada e apresentada por alunos do $10{ }^{\circ}$ ano, no Laboratório de Química. Nela, os alunos tiveram a oportunidade de relacionar, com a Química e a Bioquímica, algumas das actividades dos nossos antepassados (o fabrico de bebidas alcoólicas e de cosméticos, a conservação de alimentos com sal e açúcar, o comércio das especiarias). Produziram cerveja, vinho, aguardente, presunto, enchidos, sal, açúcar de cana, caramelo, compotas, licores, perfumes, sabão, cremes e óleos de massagem. Em todas estas actividades aplicaram Técnicas Laboratoriais de Química tais como: infusões, filtrações, secagens, destilações, macerações, cristalizações, prensagens, extracções em soxhlet...
Compreenderam melhor a osmose, as reacções de saponificação e a caramelização e construíram alguns modelos de moléculas - limoneno, vanilina, cafeína, butanoato de etilo, etanol, maltose e sacarose - e do cloreto de sódio.

E assim decorreram três dias repletos de Cheiros, Aromas, Sabores, Química, Convívio, História, Pesquisa, Descoberta, Criatividade, Conhecimento, Prazer...

Março de 2007

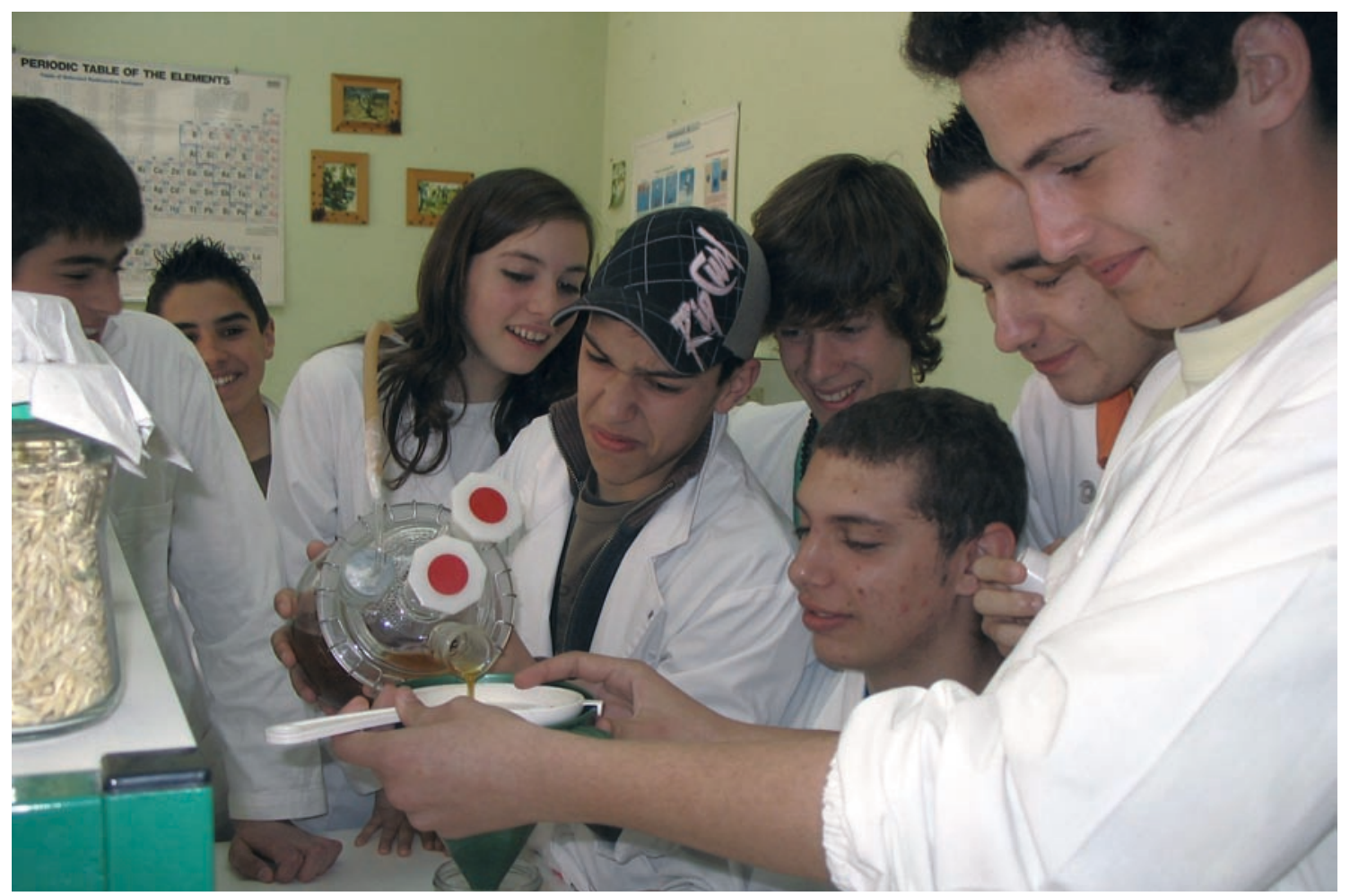

Produção de cerveja

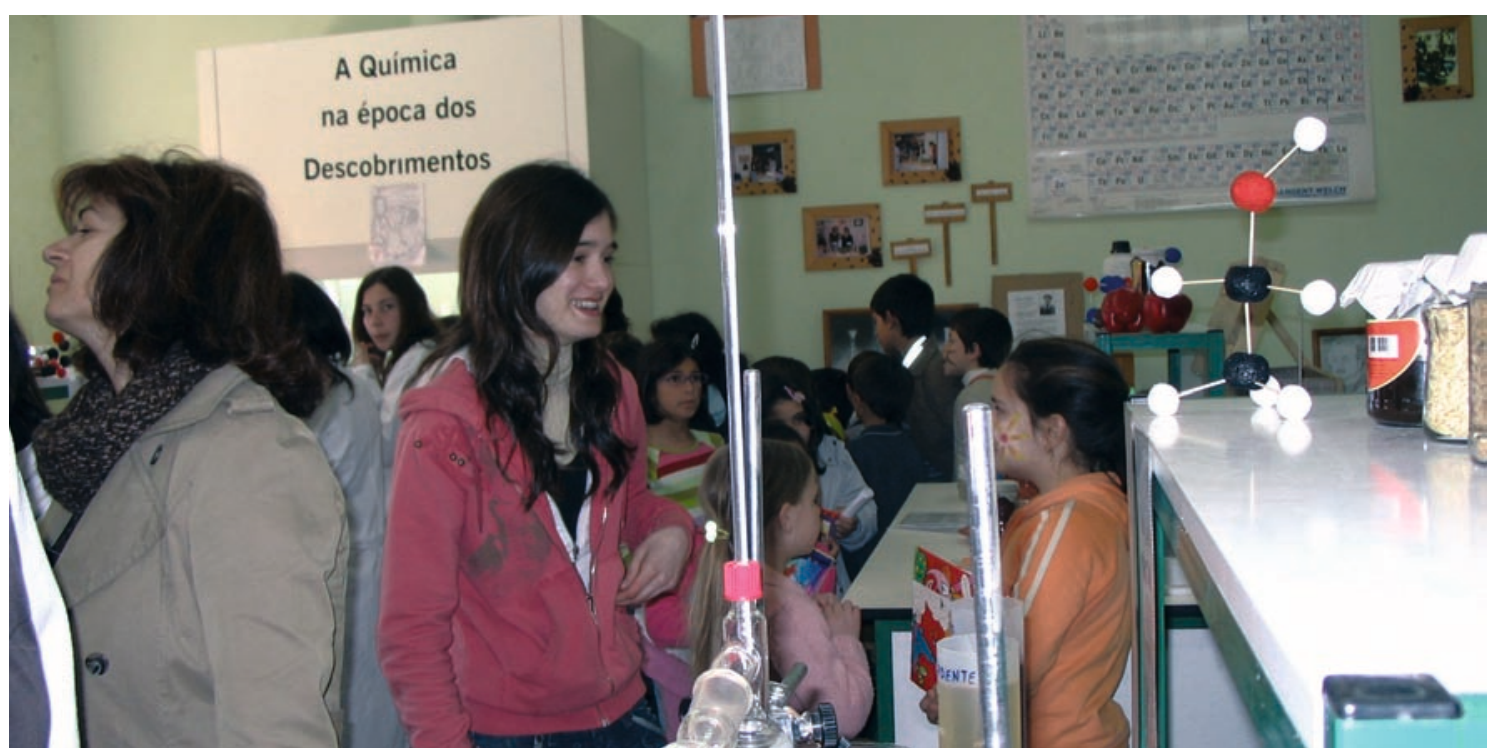

Destilação do vinho 